Article

\title{
Uncertain Hybrid Multiple Attribute Group Decision of Offshore Wind Power Transmission Mode Based on theVIKOR Method
}

\author{
Nansheng Pang and Wenjing Guo * \\ School of Economics and Management, North China Electric Power University, Beijing 102206, China; \\ pnstg@ncepu.edu.cn \\ * Correspondence: gwj417@ncepu.edu.cn
}

Received: 27 August 2019; Accepted: 15 October 2019; Published: 5 November 2019

\begin{abstract}
With the increasing scale of offshore wind power, large-capacity and long-distance offshore wind power will be a trend in the future development of wind power. However, compared with onshore wind power transmission, offshore wind power transmission is more difficult and costly. Therefore, it is of great practical significance and urgency to select the appropriate power transmission mode to realize the long-distance transmission of large-capacity offshore wind power. Since the selection of offshore wind power transmission mode is a multiple attribute decision making problem, in this paper, the technical characteristics of high voltage alternating current (HVAC) and voltage source converter based on high voltage direct current (VSC-HVDC) that are already in use and hybrid HVDC that is possible to be used in offshore wind power transmission in the future are discussed. Based on this analysis, the reliability, economy and construction difficulty of offshore wind power transmission mode are systematically analyzed, and VIKOR method is applied to group decision-making for the selection of offshore wind power transmission mode. The main contributions of this paper are as follows: (1) the characteristics of large-capacity and long-distance offshore wind power transmission are studied, and the evaluation system with multiple indexes including a large number of qualitative indexes is constructed from the technical, economic and social aspects. In order to deal with difficult problems of fuzzy information, interval numbers, language variables, intuitionistic fuzzy numbers and other data types are used to deal with them effectively. (2) In the VIKOR method, because the expert weights are unknown in group decision-making, the expert trust function is used to objectively determine the weight of each expert. (3) The group decision-making analysis of actual case of offshore wind power plant is carried out by using expert knowledge and VIKOR method. The case shows that this method is simple, reasonable and practical.
\end{abstract}

Keywords: offshore wind power; HVAC; VSC-HVDC; hybrid HVDC; VIKOR; group decision-making

\section{Introduction}

In recent years, the problem of energy exhaustion and environmental pollution has become more and more serious. New energy power generation has become a priority power project for all countries. Wind power generation has also become a priority clean energy for all countries. Since offshore wind farms are far away from the coast and have less visual interference, they are also rich in resources, have high annual utilization hours, stable wind speed, no land resources and less impact on ecological environment. They have developed rapidly in developed areas such as Europe and the United States.

With the increasing scale of offshore wind power, large-capacity and long-distance offshore wind power will be a trend in the future development of wind power. Compared with onshore wind power transmission, offshore wind power transmission is more difficult and costly. The submarine structure 
is not as stable as the land, which poses some obstacles to the installation of offshore wind power plant structure. At the same time, due to the high humidity and high salinity of the sea air and seawater, wind power equipment and submarine cable are required to have a higher corrosion resistance [1]. Traditional high voltage alternating current (HVAC) transmission technology is mature and widely used in built offshore wind farms, but its loss increases with the increase of transmission distance. Therefore, it is of great practical significance and urgency to select suitable transmission mode to realize long-distance transmission of large-capacity offshore wind power. With the development of science and technology, the technologies of voltage source converter based on high voltage direct current (VSC-HVDC) transmission and hybrid high voltage direct current(Hybrid HVDC) transmission are gradually developed, which provides a guarantee for long-distance offshore power transmission.

At present, there is abundant research on transmission technology, and a variety of transmission technologies have been applied to offshore wind power transmission process. Many scholars have studied VSC-HVDC based on a voltage source converter (VSC). The main components, topologies, technical performance and control strategies of the VSC-HVDC system are introduced. Korompili, Wu and Zhao gave the converter control system and control strategies, and focused on the control method adopted by VSC-HVDC to meet the requirements of low-voltage ride through (LVRT) and frequency regulation of network coding [2]. Wu, Wang, $\mathrm{Xu}$ and Wang introduced the structure, control methods and application of modular multi-level converter (MMC), discussed the control strategy of VSC-HVDC transmission system, and focused on the double closed-loop vector control and direct power control, the control methods for unbalanced grid voltage, deadbeat control, etc. [3]. Qiu, Fan, Cheng and Qiao proposed a flexible control strategy to realize offshore power transmission. AC voltage control method was used for rectifier, DC voltage control method was used for inverter, and the performance of this strategy was carried out in emulation and analysis [4]. Moawwad, El Moursi and Xiao proposed a management scheme based on VSC and a new control strategy. By setting up an experimental device for the control strategy and management scheme, the feasibility and effectiveness of the strategy and scheme were verified by simulation $[5,6]$. With the continuous development of electronic devices and the wide application of HVDC transmission technology, hybrid HVDC transmission system has become a research hotspot. Tang and Xu proposed a topology structure with DC line fault clearance capability based on the study on the hybrid HVDC transmission of a line commutated converter(LCC) and modular multilevel converter(MMC), using power systems computer aided design (PSCAD) to model the hybrid HVDC system, which verifies the validity of the control system and start-up scheme [7]. Torres-Olguin, Molinas and Undeland studied the feasibility of Hybrid HVDC transmission that is combined by the traditional LCC and VSC. Under various conditions, the proposed control strategy was tested [8]. Jung, Cui, Lee, \& Sul proposed a new topological structure of hybrid HVDC transmission, it can reduce the system cost and operation loss under the existing conditions, but it can still maintain the capability to cope with a DC short-circuit fault [9]. In order to improve the dynamic performance of the system, Zhou, Yang and Wang modeled, analyzed and controlled the offshore wind power that adopts hybrid HVDC transmission. The corresponding mathematical model is derived by using state function. Considering different control modes, the dynamic analysis of the AC current of the rectifier is carried out, the control scheme is designed according to the analysis results, and the superiority of the control scheme is verified by examples, which lays a foundation for the hybrid direct current transmission as an offshore transmission mode [10].

There are differences in economy, loss, stability and fault response among different transmission modes. Comparing and analyzing the transmission modes in many aspects to determine the advantages and disadvantages of each mode is more conducive to the selection of transmission modes in wind farms. By means of technical and economic analysis, Ruddy, Meere and O'Donnell compared and analyzed the power loss, reliability and investment cost of low Frequency AC transmission and VSC-HVDC [11]. From the perspective of economic value, Eeckhout, Hertem, Reza, Srivastava and Belmans and Sousa, Dos Santos, Jardini, Casolari and Nicola considered the relevant economic benefits of transmission modes, established models to observe the impact of different voltage grades, transmission distances and 
transmission power on costs, analyzed and compared the HVAC transmission mode and VSC-HVDC transmission [12,13]. Negra, Todorovic and Ackermann compared transmission losses of HVAC and VSC-HVDC transmission under different voltage levels and distances and drew the conclusion that transmission power of VSC-HVDC transmission is lower than that of HVAC transmission [14]. Wang and Nguyen This made a comparative analysis of the stability of large offshore wind farms based on HVAC and HVDC transmission. The eigenvalue technique and root-loci plot were used to analyze the reaction of three-phase short-circuit fault in these two ways. The system method is used to evaluate them, and a conclusion is drawn that the stability of HVDC transmission mode is better [15]. Chou, Wu, Han and Lee synthetically analyzed the frequency response of the transient voltage of a large offshore wind farm in Taiwan and simulated its HVAC and HVDC transmission side by using simulation method. The simulation results show that the HVDC can provide better voltage and frequency response and reduce the impact of grid faults on wind farms, so it has higher reliability [16].

Currently, emerging transmission technology has been gradually applied to practical projects. An, Tang and Wang summarized the key technologies of VSC-HVDC and the key technologies and equipment of DC grid, introduced the HVDC transmission projects built or planned to be built in China, and provided valuable reference for the development and application of VSC-HVDC transmission technology [17]. Gustavsen and Mo proposed a method of adjusting the operating voltage of cables to reduce the high loss caused by capacitor charging current under long-term high voltage AC connection. It was applied to a $200 \mathrm{~km}$ and $320 \mathrm{MW}$ offshore wind power plant. The result showed that the annual transmission loss is reduced by $9 \%$ in this way [18]. Benasla, Allaoui, Brahami, Denaï and Sood briefly introduced the HVDC transmission lines between North Africa and Europe, as well as other large-scale projects applying HVAC and HVDC transmission, pointed out some problems existing in the operation and control of HVDC transmission lines, and proposed solutions to these problems [19]. Ingemansson, Wheeler, Macleod, Gallon and Ruiton introduced a high voltage transmission line in Sweden, it used VSC-HVDC transmission to transfer electric energy from Arkeryd to Hurva. The transformer designed on this line based on VSC technology was described, and another Hybrid HVDC transmission line which will be designed and built soon was introduced [20]. Rao introduced the application of VSC-HVDC transmission mode in Nan-ao islands in China, and gave the corresponding system configurations and control strategies, which indicated this technology has great significance for the transmission of offshore wind power [21].

At present, in the selection and research of offshore wind power transmission modes, most of them are considered from the economic point of view, such as Eeckhout et al. and Serrano, Burgos and Riquelme, although they considered the line losses, transmission capacity, reliability and other factors of transmission modes in the analysis, in actual modeling and analysis, because the fuzzy information and uncertain data of these indexes cannot be effectively processed, the cost model can only be established based on the economic indicators such as equipment cost, maintenance cost and construction cost, which led to the transmission mode of the offshore wind farm being selected [12,22]. Due to the excessive emphasis on cost and neglect of other factors, this choice will inevitably result in a large amount of information loss and one-sided decision-making. The selection of offshore wind power transmission mode is a multiple attribute decision-making problem involving technology, economy, society and other aspects, which requires comprehensive evaluation and selection from multiple perspectives and attributes. In order to solve the above problems, this paper adopts VIKOR method to select the mode of offshore wind power transmission. This method can not only effectively deal with uncertain data and fuzzy information in the decision-making process, fully consider the impact of multi-attribute indexes on the decision-making results, but also make group decision based on many other experts' opinions to obtain a compromise.

The VIKOR method has great advantages in solving decision-making problems with conflicting and non-generable standards. To evaluate alternatives according to all established standards and to determine compromise that is closest to the ideal. More and more scholars are studying the VIKOR 
method to solve the related decision-making problems. Wan, Yuan and Dong proposed a linguistic hesitant fuzzy algorithm to deal with multi-criteria decision-making problems, put forward a new order relationship and a series of new distance measures, and defined some desirable properties of distance, established optimization models and deduced objectively criteria weights. Finally, an example of the intelligent transportation system is analyzed to verify the feasibility and validity of this method [23]. Prakash and Barua proposed a composition model based on the fuzzy analytic hierarchy process (FAHP) and VIKOR to evaluate and rank the selection criteria. Taking the selection decision-making of logistics partners of an Indian company as an example, the sensitivity analysis is carried out by using this composition model, and the robustness of the method is verified [24]. You, You, Liu and Zhen proposed the ITL-VIKOR method for multi-criteria supplier selection based on interval 2-tuple linguistic information. The feasibility and practicability of this method were verified by an example of supplier selection. The result showed that this method is more suitable for the supplier selection problem under fuzzy, uncertain and incomplete information environment [25]. Gupta used the VIKOR method to rank airlines according to their reliability, safety, ticket price and other attributes. Through extensive literature review and analysis, it is concluded that quality of service attributes is of great significance for airline managers to solve problems [26]. Shojaei, Seyed Haeri and Mohammadi used the VIKOR method to establish an effective evaluation model for airport performance worldwide [27]. Seyed Haeri and Alireza used the VIKOR method to select materials for sustainable development products [28]. Rajesh used the VIKOR method to build a model to measure the elastic barriers of supply chain [29]. Ali, Razi, Felice, Sabir and Petrillo assessed the social, environmental and economic impacts of smog based on VIKOR method [30]. Mateusz, Danuta, Małgorzata, Mariusz and Kesra used technique for order preference by similarity to an ideal solution (TOPSIS) and VIKOR to compare and analyze the sustainable development capacity of European countries, which had the important value in operability evaluation of concept of sustainable development [31]. The VIKOR method is widely used in all aspects of technical and economic life, but no scholar has used this method to evaluate and select transmission modes.

In this paper, group decision-making method based on the VIKOR method is introduced into the comprehensive evaluation and selection of offshore wind power transmission modes. At the same time, innovations are made in the method. Firstly, the entropy method is used to calculate the index weight for different types of attribute values information. Secondly, the expert trust function is established to give experts weight. Thirdly, all indexes are finally summed as intuitionistic fuzzy numbers, which are aggregating operators, and the final calculation results are obtained. This method solves the disadvantage of uncertain index data and has certain pioneering significance.

The VIKOR method is widely used in various selection evaluation problems, such as renewable energy evaluation, project maintenance grade evaluation, construction risk evaluation, etc. It is seldom used in transmission mode evaluation and selection for offshore wind power. This paper verifies the applicability of this method in this field.

The structure and content of this paper are as follows: Section 2 studies the components, transmission principles, advantages, disadvantages and applications of three types of offshore wind power transmission modes: HVAC, VSC-HVDC and hybrid HVDC; Section 3 expounds the basic principles of the VIKOR method, and introduces the interval number, intuitionistic fuzzy number, linguistic variables and other operational rules. Based on the principle of entropy, the calculation methods of attribute objective weights, expert objective weights and corresponding algorithm steps are proposed. Section 4 constructs the index model of offshore wind farm transmission, and explains the relevance of each index to the problem. Section 5 uses VIKOR method to analyze an example of offshore wind farm, and obtains the corresponding results and compares them with the actual situation; Section 6 summarizes the foregoing content of this paper and looks forward to the future research of related technologies. 


\section{Offshore Wind Power Transmission Mode}

On the premise that the traditional transmission modes can not meet the requirement of long-distance offshore wind farm power transmission, the innovation of science and technology has brought new modes of transmission for offshore wind power, in addition to the traditional HVAC transmission mode, the VSC-HVDC transmission and hybrid HVDC transmission mode are gradually applied to offshore wind power projects to provide more powerful support for power transmission in terms of economy and reliability. This paper mainly introduced three transmission modes: HVAC, VSC-HVDC and hybrid HVDC.

\subsection{High Voltage AC Transmission Mode}

High voltage alternating current (HVAC) is a mature technology in offshore wind power transmission. The world's earliest offshore wind farm, Vindeby offshore wind power in Denmark, uses HVAC to integrate electricity into transmission systems of Germany and Sweden [32]. So far, most of the offshore wind farms that have been built use the HVAC mode to transmit electricity.

HVAC system consists of AC collector bus, offshore booster station and reactive compensation devices, $\mathrm{AC}$ cables, onshore substation and reactive compensation equipment [33]. The principle of this transmission mode is to collect the power generated by wind power turbines through AC collector lines, then raise the voltage through offshore booster stations and finally transmit the power to onshore substations through submarine cables. The principle of this transmission system is shown in Figure 1.

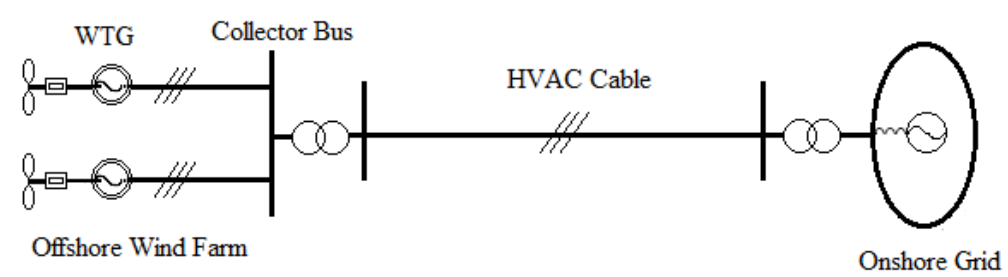

Figure 1. Offshore wind farm with a high voltage direct current (HVDC) transmission system.

This transmission mode has a simple structure, low cost, rich operation and practical experience for many years. It has great advantages in terms of short-distance, small-capacity wind power transmission and grid-connection.

According to the planning of offshore wind power at home and abroad, the location of offshore wind farms is gradually becoming deeper-sea, and the capacity of offshore wind farms is increasing. However, there are some problems in high-voltage AC transmission mode for long-distance and large-capacity transmission: (1) AC cables have an obvious capacity effect, which produces larger charging current, which leads to lower transmission efficiency of cables, and increases with transmission distance. Therefore, reactive compensation devices must be added to the transformer substations at both ends of the cable, which not only increases the cost, but also increases the construction difficulty [33]. (2) High voltage AC transmission means that the wind farm and its land power distribution system must keep synchronism. No matter which end of the system fails, it will directly affect the other end. With the increase of installed capacity and transmission distance of the wind farm, the reliability would reduce greatly.

\subsection{VSC-HVDC Transmission Mode}

Voltage source converter based high voltage direct current transmission (VSC-HVDC) is a new transmission technology based on pulse-width modulation (PWM) and insulated gate bipolar transistor (IGBT) [34,35].

The German BorWin2 offshore wind power project, it realized grid-connected transmission in 2015, adopted VSC-HVDC transmission mode. The alternating current generated by wind turbines is converted into direct current through the converter, low-loss transmission to the mainland and then 
converted back to AC input to the German power grid [36]. At present, VSC-HVDC technology has been applied in engineering and commerce in China. Three VSC-HVDC transmission lines with $160 \mathrm{kV}$, $100 \mathrm{MW}, 200 \mathrm{~km}$ (o/h line), $50 \mathrm{~km}$ (onshore cable) and $32 \mathrm{~km}$ (offshore cable) lengths were completed in 2013 [37].

The principle of this transmission mode is that the power generated by wind turbines is transferred to the AC bus through a transformer, and the phase angle and amplitude of the output voltage are changed by the switch of electronic devices in the VSC of high controllability. The active and reactive power on the AC side is controlled independently, and the AC power is converted to DC power, which is transmitted by DC cables to onshore converter and then converted to AC power and integrated into the onshore power grid. The principle of this transmission system is shown in Figure 2.

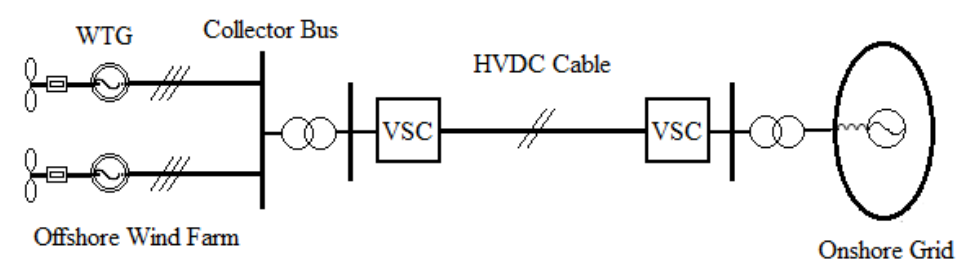

Figure 2. Offshore wind farm with a voltage source converter based on high voltage direct current (VSC-HVDC) transmission system.

HVDC transmission lines use less wire than AC lines, so it has the characteristics of low cost, low loss, large transport capacity, long service life and basically unlimited transmission distance, which is conducive to phased construction and capacity expansion [38]. HVDC transmission enables asynchronous networking between offshore wind farms and onshore power grids to suppress synchronous fault propagation. In addition to the advantages of conventional HVDC transmission, flexible HVDC transmission has its own special advantages: (1) has active power control and frequency response capability; (2) has reactive power control and voltage support capability; (3) can achieve fast response to disturbances and (4) has black start capability $[2,8,39]$. These special advantages make VSC-HVDC transmission more reliable than HVAC transmission. At the same time, VSC-HVDC transmission mode has the characteristics of modularity, which is more convenient in construction. However, when using the VSC-HVDC transmission mode, the cost of large-capacity converters and other equipment is higher, and the economy is slightly worse.

\subsection{Hybrid HVDC Transmission Mode}

Hybrid high voltage direct current transmission (Hybrid HVDC) combines the traditional HVDC transmission mode with flexible HVDC transmission mode, making full use of the advantages of the two HVDC transmission modes. The rectifier side uses a line commutated converter (LCC) converter station. The inverter side adopts a new hybrid transmission mode of the VSC converter station $[40,41]$.

The electrified railway and power system interconnection project in Bremen, Germany, adopts the hybrid DC transmission mode. The rectifier side is LCC composed of thyristors, the inverter side is VSC, the transmission capacity of the system is $100 \mathrm{MW}$, the rated voltage is $10 \mathrm{kV}$, and the rated current is $5 \mathrm{kA}$. The constant direct current voltage control method is adopted on the rectifier side and the active and reactive power control method is adopted on the inverter side [42].

The main part of HVDC system is VSC, including transformers, filters, converter reactor and DC capacitance, and LCC, including transformers, filters and flat wave reactors. The principle of this transmission mode is that the power generated by wind turbines is concentrated on AC bus through transformers, rectify by wind farm side converter station, pass through DC cables, and then connect to the grid through invert of invert side converter station. The principle of this transmission system is shown in Figure 3. 


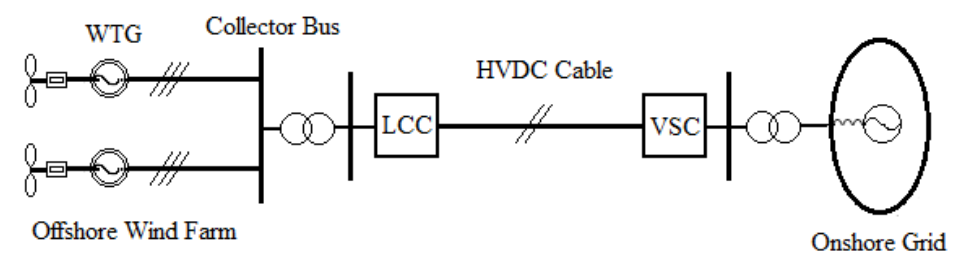

Figure 3. Offshore wind farm with a hybrid HVDC transmission system.

A hybrid HVDC system integrates the flexibility and rapidity of flexible HVDC system control, and combines the low loss and low cost of the traditional HVDC system, which reduces the influence of the backend systems on the transmission system, reduces the loss and the cost of construction, can connect wind farms and power grids with larger capacity and has better flexibility, reliability, controllability and economy [43]. This method has not been applied to offshore wind power projects because it is in the stage of development, and its technology maturity is low.

With the rapid development of offshore wind power, hybrid HVDC transmission technology with high reliability will become an effective way to improve the reliability and flexibility of power transmission by connecting many large offshore wind farms with load centers. At present, hybrid HVDC transmission technology has been identified as one of the key technologies in the construction of a super-grid in Europe [44].

\section{Selection of Evaluation Indexes for Offshore Wind Power Transmission}

The transmission of electric energy is closely related to the realization of offshore wind power projects. The evaluation and selection of transmission mode is the key to realize the transmission of electric energy, and the selection of indexes is the focus of evaluation and selection of transmission mode. Different indexes reflect the different characteristics of transmission modes. When choosing transmission modes, appropriate indexes can provide better measurement standards to make the selected transmission modes more in line with the actual situation of offshore wind farms, which is more conducive to the continuous progress of the project. According to the existing literature and the selection requirements of offshore wind farm transmission mode, from technical value, economic value and social value, the following indexes are selected to construct the evaluation index model of offshore wind farm transmission $[13,14,17]$. The evaluation indexes system for offshore wind power transmission is shown in Figure 4.

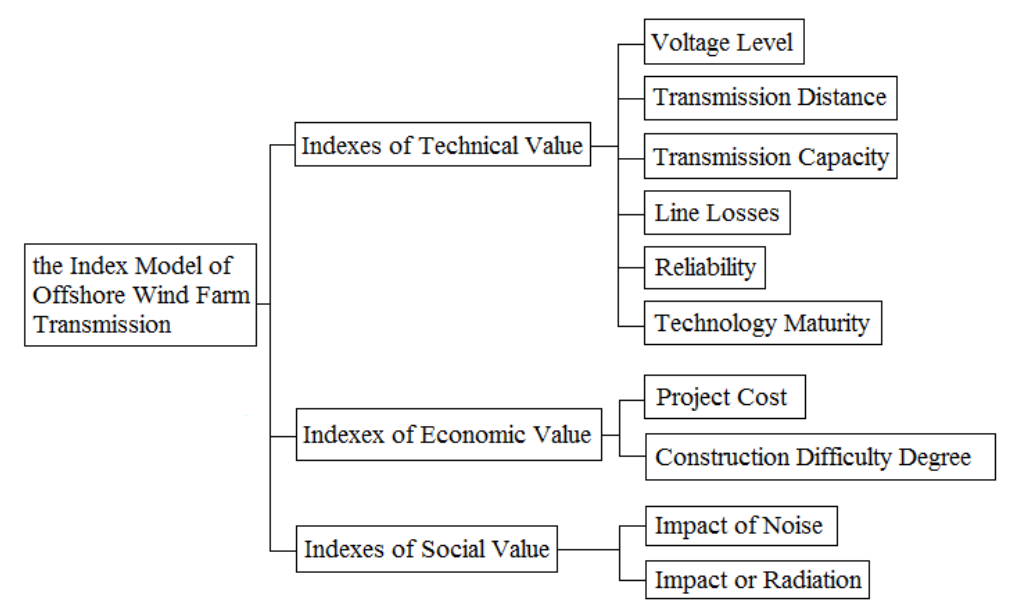

Figure 4. The index model of offshore wind farm transmission. 


\subsection{Indexes of Technical Value}

This paper mainly chose the indexes from two aspects: technical advancement and technical applicability, including voltage level, transmission distance, transmission capacity, line loss, reliability, technology maturity, etc.

Voltage level is the highest voltage level that can be reached on power lines. In order to reduce the loss of the transmission line in the long distance transmission line, transmission current should be reduced; and transmission voltage should be increased in order to ensure certain amount of power to users at the same time. The voltage of modern long-distance transmission is very high. Currently, the common voltage of high-voltage transmission lines is $500 \mathrm{kV}$, AC lines can reach up to $765 \mathrm{kV}$, and DC lines can reach up to $800 \mathrm{kV}$ [45]. The voltage level is limited by the insulation performance of the transmission line. The higher the voltage is, the higher the insulation performance requirements of the transmission line will be, and the higher the cost of line construction will be. The higher the transmission voltage, the higher the voltage on the transformer, and the higher the requirements for transformers. Under technical and economic constraints, the higher the voltage, the smaller the loss and the better the transmission performance. When transporting electric energy in offshore wind farms, various factors should be considered comprehensively, such as the size of transmission power, distance, technical and economic requirements, etc. In the controllable range, the appropriate transmission voltage should be selected according to different conditions.

Transmission distance refers to the distance from the power collection system of the wind power plant to an onshore power grid. From the point of view of the built and being built offshore wind farms in the world, the development trend is toward the far sea and the deep sea, especially in Britain and Germany, where the development level of offshore wind power is relatively high, their development of deep sea wind farms has begun. Denmark, the Netherlands and Germany are currently studying the wind farm built 100 kilometers offshore from the UK [45]. As far as China is concerned, the wind energy resources in the coastal zone are slightly worse than those in the European sea area. In order to reduce the roughness of the sea surface and improve the quality of the wind resources, the trend of developing the deep sea from intertidal zones to inshore has been gradually developed [1]. Brook no delay. Therefore, transmission distance is an important factor to be considered in the selection of transmission technology. Technologies that provide longer transmission distances are more suitable for deep-sea wind power projects.

Transmission capacity refers to the maximum power allowed to transmit under normal conditions in power lines, which is usually higher than the installed capacity of wind farms. Since the transmission power transmitted by power lines is related to the power quality, power loss, the allowable temperature of the wire and the stability of the power system, this limit is determined by comprehensive judgment of many factors such as economy, technology and so on. Due to the different length of the line and the different position of the line in the system, the emphasis of consideration is also different. In order to improve the transmission capacity of transmission lines, the ways of increasing voltage and reducing current are usually adopted to reduce losses, but the improvement of voltage is limited by the development of insulation technology. It can be expected that with the improvement of insulation technology, the voltage of transmission lines can be further improved, the loss of transmission lines can be further reduced and the transmission capacity of lines can be further increased.

Line losses refer to the energy loss caused by the transmission of electric energy through transmission lines. In addition to power transmission lines, other transmission and transformation equipment in power network, such as transformers, also produce power loss. In AC transmission system, capacitive current will be generated during the transmission of electric energy, resulting in a significant reduction in the transmission performance of cables and an increase in losses. In contrast, the loss rate of DC cables is slightly lower, but it also exists in the process of converter commutation. Hybrid HVDC uses the rectifier side LCC to reduce losses.

Reliability refers to the ability of technology to fulfill specified functions under specified conditions and within specified time. Reliability of transmission mode refers to its ability to operate safely, stably 
and continuously live. The reliability of transmission mode mainly involves the reliability of submarine cables and related equipment. At the same time, adopting certain technical measures can also improve the overall reliability of transmission mode. Compared with VSC-HVDC and hybrid HVDC, HVAC lacks some technical measures to guarantee its reliability, such as black start and dynamic voltage control, therefore, its reliability is low. Hybrid HVDC technology combines the advantages of flexible HVDC technology and traditional HVDC technology, it has high reliability.

Technology maturity refers to the industrialization practical level of technological achievements in terms of the technology level, technological processes, supporting resources and technical life cycle. It also refers to the development status of technology relative to a specific system or project, which reflects the degree to which technology satisfies the expected goal of the project. The purpose of technology maturity evaluation is to accurately evaluate the state of technology development, improve the scientificity of management decisions. Mature technology is more conducive to controlling the project cost, time limit and quality, and reduce the application risk of technology in engineering. Offshore wind power is developing rapidly in China. Advanced technology is gradually applied to offshore wind power projects. At present, China's offshore wind power projects have basically adopted high-voltage AC transmission technology. Flexible direct current transmission technology has been successfully applied to offshore wind power in some developed countries, but China has not yet used it. Hybrid direct current transmission technology as a new technology has a low maturity.

\subsection{Indexes of Economic Value}

The indexes of economic value mainly refer to the index of investment, cost and time cost of technology, including project cost and construction difficulty degree.

Project cost refers to the construction price of a project. It refers to the anticipated or actual total cost required to complete the construction of a project, which generally includes the purchase cost of equipment, construction cost, installation cost and other expenses. In investment decision, project cost is usually the most intuitive economic index. For offshore wind power transmission system, it mainly involves the purchase and installation costs of cable, booster stations, converters and other equipment. Within other constraints, investors are more likely to choose lower-cost options to reduce risk.

The construction difficulty degree is related to the cost, quality and construction period of the project. The laying of submarine cables and the installation and construction of necessary equipment are the main design of offshore transmission line construction. Compared with land transmission lines, offshore wind power lines are difficult to design and construct because of their special geographical environment, which has a great impact on investment decisions of power companies. For the three transmission modes of high voltage AC, flexible DC and hybrid DC, there are differences in construction difficulty due to different technical characteristics and composition structure. The measurement of construction difficulty is the construction period. The longer the construction period is, the more difficult the construction is, and vice versa.

\subsection{Indexes of Social Value}

Choices are made mainly from a social perspective, including noise and radiation effects.

Noise and radiation effects are environmental problems that should be considered in any project while creating economic benefits. Due to the large scale of offshore wind farms, the development, implementation and operation of offshore wind farms will inevitably affect the ecological environment of the engineering sea area, such as marine fishery, sound environment, seabed topography and electromagnetic radiation during the laying of submarine cables and the construction of equipment. When choosing the scheme, we should try our best to adopt the scheme which has little impact on the environment so as to reduce the damage to the ecological environment. 


\section{The VIKOR Method and Hybrid Multiple Attribute Group Decision-Making}

\subsection{Basic Principles of the VIKOR Method}

The VIKOR [46] method is a compromise sorting method based on the ideal point method proposed by Professor Opricovic of Yugoslavia in 1998. It is characterized by considering the maximization of group benefits, the minimization of individual regrets and the integration of subjective preferences of decision makers. The VIKOR method is a compromise sorting method to solve the hybrid multiple attribute decision-making problem.

The evaluation principle of the VIKOR method is to calculate the distance between alternatives and ideal points according to the Lp-metric aggregate function.

$$
L_{p i}=\left\{\sum_{j=1}^{q}\left[\frac{w_{j}\left(f_{j}^{*}-f_{i j}\right)}{f_{j}^{*}-f_{j}^{-}}\right]^{p}\right\}^{\frac{1}{p}}, 1 \leq p \leq \infty, i \in M
$$

In Equation (1), $w_{j}$ is the weight of target $w_{j}, f_{i j}$ is the attribute value of target $X_{j}$ in alternative $i, f_{j}^{*}$ is the positive ideal point of target $X_{j}$, choosing the optimum value of each alternative in target $X_{j}$ and $f_{j}^{-}$is the negative ideal point of target $X_{j}$ and chooses the worst value of each alternative in target $X_{j}$. The meaning of $L_{p i}(1 \leq p \leq \infty)$ represents the weighted combination deviation of each target $f_{i j}$ from the ideal point. When $p=1, L_{1 i}$ denotes 1 norm; $p=2, L_{2 i}$ denotes 2 norm and $p=\infty, L_{\infty i}$ denotes infinite norm. Since $L_{2 i}$ denotes the geometrical distance in a general sense, when $1 \leq p \leq \infty$, $L_{1 i}$ and $L_{\infty i}$ denote the bound of the distance, namely $L_{1 i} \leq L_{2 i} \leq L_{\infty i}$. By minimizing $L_{1 i}$ and $L_{\infty i}$ to solve the optimal solution, these two optimal solutions are generally different, and they are all Pareto solutions. When $1 \leq p \leq \infty$, all Pareto solutions lie between these two Pareto solutions.

The VIKOR method is to select a Pareto solution between the two Pareto solutions as a compromise. Since the group benefit $S_{i}$ value of each alternative is equal to $L_{1 i}$, and the individual regret value $R_{i}$ is equal to $L_{\infty i}$, the corresponding compromise alternative can be obtained by setting the ratio coefficients between group benefit and individual regret value, which reflects the preference of decision makers. This compromise alternative can be accepted by decision makers.

Taking two objectives as an example, the compromise solution determined by the VIKOR method can be represented in the target space by the following Figure 5: $A^{\bullet}$ is the ideal point, $f_{1}^{*}$ and $f_{2}^{*}$ are the optimal values in the first objective and the second objective attribute values respectively and $A^{c}$ is the closest compromise solution to the optimal solution $A^{\bullet}$ in the Pareto solution determined by 1 norm and infinite norm. The compromise solution of $A^{c}$ is the result of compromise and concession between the two objectives. The corresponding amount of compromise is $\Delta f_{1}=f_{1}^{*}-f_{1}^{c}$ and $\Delta f_{2}=f_{2}^{*}-f_{2}^{c}$, respectively. 


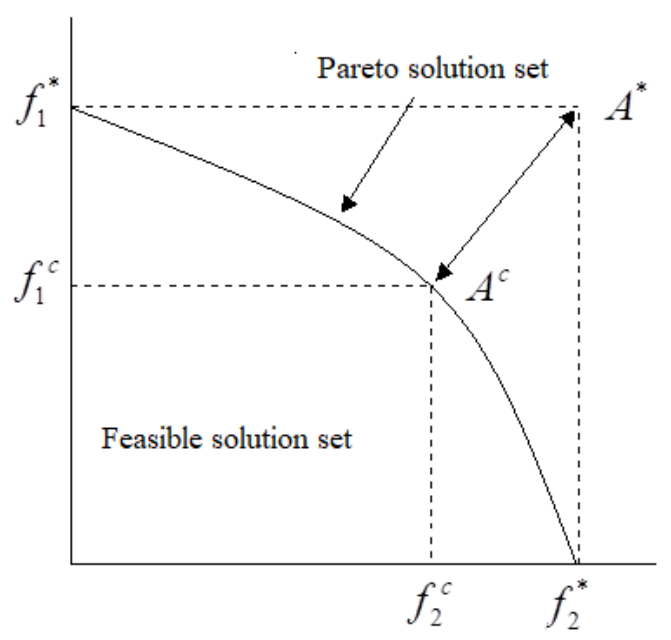

Figure 5. Compromise diagram.

\subsection{Hybrid Decision Information}

\subsubsection{Concepts of Interval Numbers and Intuitionistic Fuzzy Numbers}

$x=\left[x^{l}, x^{u}\right]=\left\{x \mid x^{l} \leq x \leq x^{u}, x^{l}, x^{u} \in R\right\}$ is called an interval number on $R, x^{l}$ is the lower bound of the interval, $x^{u}$ is the upper bound of the interval and $R$ is the real field. When $0<x^{l}<x^{u}, x=\left[x^{l}, x^{u}\right]$ is called number of positive closed intervals; when $x^{l}=x^{u}$, the interval number degenerates to real number. Interval number is a set of all real numbers on closed intervals.

Suppose there are any two interval numbers $a=\left[a^{l}, a^{u}\right]$ and $b=\left[b^{l}, b^{u}\right]$, then the distance between $a$ and $b$ is.

$$
d(a, b)=\sqrt{\frac{1}{2}\left[\left(a^{l}-b^{l}\right)^{2}+\left(a^{u}-b^{u}\right)^{2}\right]}
$$

$A=\left\{\left[x, \mu_{A}(x), v_{A}(x)\right] \mid x \in X\right\}$ is called an intuitionistic fuzzy set in $X . \mu_{A}(x)$ and $v_{A}(x)$ are membership and non-membership of element $x$ belonging to $A$ in $X, \mu_{A}(x) \in[0,1], v_{A}(x) \in[0,1]$, $0 \leq \mu_{A}(x)+v_{A}(x) \leq 1, \forall x \in X$. In addition, $\pi_{i j}=1-\mu_{A}(x)-v_{A}(x)$ is called hesitancy degree or uncertainty degree of element $x$ belonging to $A$ in $X$. An ordered pair composed of the membership and non-membership of element $x$ in $X$ belongs to $A$ is called the intuitionistic fuzzy number [47].

Generally, intuitionistic fuzzy numbers are denoted as $a=\left(\mu_{a}, v_{a}\right), \mu_{a} \in[0,1], v_{a} \in[0,1]$ and $0 \leq \mu_{a}+v_{a} \leq 1$.

Suppose there are any two intuitionistic fuzzy numbers $a=\left(\mu_{a}, v_{a}\right)$ and $b=\left(\mu_{b}, v_{b}\right)$, then the hamming distance between $a$ and $b$ is,

$$
d(a, b)=\frac{1}{2}\left(\left|\mu_{b}-\mu_{a}\right|+\left|v_{b}-v_{a}\right|+\left|\left(1-\mu_{b}-v_{b}\right)-\left(1-\mu_{a}-v_{a}\right)\right|\right)
$$

\subsubsection{Processing of Language Variables}

The language variable [48] is expressed in the form of the natural language. Expert group members use familiar simple language phrases to judge alternatives qualitatively, which is more in line with the individual initiative of individual experts. The data of linguistic variable types are usually processed in a transformational way, where the information of semantic evaluation is transformed into intuitionistic fuzzy numbers. The linguistic variables standard and the corresponding intuitionistic fuzzy numbers are shown in Table 1. 
Table 1. Conversion of linguistic variables and intuitionistic fuzzy numbers.

\begin{tabular}{ccc}
\hline Language Variables & Signs & Intuitionistic Fuzzy Numbers \\
\hline Extreme Poor & EP (Extreme Poor) & $(0.05,0.95,0.00)$ \\
Very Poor & VP (Very Poor) & $(0.15,0.80,0.05)$ \\
Poor & P (Poor) & $(0.25,0.65,0.10)$ \\
Medium Poor & MP (Medium Poor) & $(0.35,0.55,0.10)$ \\
Medium & M (Medium) & $(0.50,0.40,0.10)$ \\
Medium Good & MG (Medium Good) & $(0.65,0.25,0.10)$ \\
Good & G (Good) & $(0.75,0.15,0.10)$ \\
Very Good & VG (Very Good) & $(0.85,0.10,0.05)$ \\
Extreme Good & EG (Extreme Good) & $(0.95,0.05,0.00)$ \\
\hline
\end{tabular}

\subsection{Decision Matrix Normalization}

Considering the multi-attribute group decision-making problem, suppose alternatives set as $A_{i}(i=1,2, \ldots, m)$, attributes set as $X_{j}(j=1,2, \ldots, n)$ and decision makers set as $d_{k}(k=1,2, \ldots, s)$. The attribute value of many data types given by experts for each objective is $x_{i j}^{k}$. Assume that attribute weights information $w_{j}(j=1,2, \ldots, n)$ is known and $w_{j} \geq 0, j=1,2, \ldots, n, \sum_{j=1}^{n} w_{j}=1$. The weight information $\lambda_{k}(k=1,2, \ldots, s)$ of the expert group is known, and $w_{k} \geq 0, k=1,2, \ldots, s, \sum_{k=1}^{s} w_{k}=1$. The hybrid decision matrix of subjective and objective evaluation of information of expert group is constructed as $D^{k}=\left[x_{i j}^{k}\right]_{m \times n}, k=1,2, \ldots, s$.

Suppose normalized decision matrix as $Z=\left(z_{i j}\right)_{m \times n}$. The most common attributes are benefit indexes and cost indexes. Make $I_{j}(j=1,2)$ represent subscript set of benefit and cost respectively, and $M=\{1,2, \ldots, m\}$, there are.

For real data, the normalized data are:

Benefit indexes:

$$
z_{i j}=x_{i j} / \max \left(x_{i j}\right), i \in M ; j \in I_{1}
$$

Cost indexes:

$$
z_{i j}=\min \left(x_{i j}\right) / x_{i j}, i \in M ; j \in I_{2}
$$

For interval numbers, the normalized data are:

Benefit indexes:

$$
\begin{aligned}
& z_{i j}^{l}=x_{i j}^{l} / \sqrt{\sum_{i=1}^{m}\left(x_{i j}^{u}\right)^{2}}, \\
& z_{i j}^{u}=x_{i j}^{u} / \sqrt{\sum_{i=1}^{m}\left(x_{i j}^{l}\right)^{2}}, ; \in M ; j \in I_{1}
\end{aligned}
$$

Cost indexes:

$$
\begin{aligned}
& z_{i j}^{l}=\left(1 / x_{i j}^{u}\right) / \sqrt{\sum_{i=1}^{m}\left(1 / x_{i j}^{l}\right)^{2}}, \\
& z_{i j}^{u}=\left(1 / x_{i j}^{l}\right) / \sqrt{\sum_{i=1}^{m}\left(1 / x_{i j}^{u}\right)^{2}}, i \in M ; j \in I_{2}
\end{aligned}
$$

\subsection{Evaluation of Attributes and Objective Weights of Individual Expert}

For the objective weights of evaluation attributes, the entropy method [49] can be used to calculate the weight, and the entropy formulas of each data type can be used to determine the weight to reflect the importance of evaluation attributes more objectively. 
Under attribute set $X_{j}\left(j \in J_{1}\right)$, the entropy of real numbers is,

$$
E\left(X_{j}\right)=-\frac{1}{\ln m} \sum_{i=1}^{m} z_{i j} \ln z_{i j}, j \in J_{1}
$$

Under attribute set $X_{j}\left(j \in J_{2}\right)$, the entropy of interval numbers is,

$$
E\left(X_{j}\right)=-\frac{1}{\ln m} \sum_{i=1}^{m} p_{i j} \ln p_{i j}, j \in J_{2}
$$

Among them, $p_{i j}=\frac{d_{i j}}{\sum_{i=1}^{m} d_{i j}}, i=1,2, \ldots, m ; j=1,2, \ldots, n, d_{i j}$ is the element in the deviation degree matrix $D=\left(d_{i j}\right)_{m \times n^{\prime}} d_{i j}=d\left(z_{i j}, z_{j}^{\bullet}\right), z_{j}^{\bullet}$ is the ideal value of benefit or cost attributes under the $j$ attribute of the normalized decision matrix $Z=\left(z_{i j}\right)_{m \times n}$.

Under the attribute set $X_{j}\left(j \in J_{3}\right)$, the entropy of intuitionistic fuzzy numbers is,

$$
E\left(X_{j}\right)=-\frac{1}{m \ln 2} \sum_{i=1}^{m}\left[\mu_{i j} \ln \mu_{i j}+v_{i j} \ln v_{i j}-\left(\mu_{i j}+v_{i j}\right) \ln \left(\mu_{i j}+v_{i j}\right)-\left(1-\mu_{i j}-v_{i j}\right) \ln 2\right], j \in J_{3}
$$

In the above formula, $J_{1}$ is the subscript set for real data attributes, $J_{2}$ is the subscript set for interval data attributes, and $J_{3}$ is the subscript set for intuitionistic fuzzy data attributes.

The weight $w_{j}$ of each attribute $X_{j}(j=1,2, \ldots, n)$ is,

$$
w_{j}=\frac{1-E\left(X_{j}\right)}{n-\sum_{j=1}^{n} E\left(X_{j}\right)}, j=1,2, \ldots, n
$$

The objective weights of individual experts can be determined by the hesitancy degree in the attribute evaluation information given by experts to alternatives. For an expert, the degree of hesitation in the evaluation information given by the expert reflects the degree of uncertainty of the expert to the evaluation object. The less hesitation, the more information experts have on the evaluation problem, and the higher the reliability of the evaluation results, the greater the weight given to the attribute. Therefore, the expert trust function can be established according to the principle of entropy to determine the objective weight of experts.

The expert trust function is defined as $B_{k}(\pi)$, and the objective weight of the individual expert is $\lambda_{k}$, there are,

$$
\begin{gathered}
B_{k}(\pi)=-\frac{\ln \left(\sum_{i=1}^{m} \sum_{j=1}^{n} \pi_{i j}^{k}\right)}{\sum_{i=1}^{m} \sum_{j=1}^{n} \pi_{i j}^{k}}, k=1,2, \ldots, s \\
\lambda_{k}=\frac{B_{k}(\pi)}{\sum_{k=1}^{s} B_{k}(\pi)}, k=1,2, \ldots, s
\end{gathered}
$$

In the formula, $\pi_{i j}^{k}$ is the hesitation value of alternative $i$ given by the $k$ decision maker in converting the evaluation information of attribute $j$ into intuitionistic fuzzy numbers. 


\subsection{Constructing Intuitionistic Fuzzy Number Group Decision Matrix}

In the group decision-making analysis, it is necessary to aggregate the decision information of expert group into group decision matrix $R=\left[r_{i j}\right]_{m \times n^{\prime}}, i=1,2, \ldots, m ; j=1,2, \ldots, n$. To achieve this goal, the intuitionistic fuzzy weighted averaging (IFWA) can be used to aggregate [50].

Let $\alpha_{k}=\left(\mu_{\alpha_{k}}, v_{\alpha_{k}}\right)(k=1,2, \ldots, s)$ be a set of intuitionistic fuzzy numbers, $\lambda_{k}(k=1,2, \ldots, s)$ be the weight vector of $\alpha_{k}(k=1,2, \ldots, s), \lambda_{k} \in[0,1], k=1,2, \ldots, s, \sum_{k=1}^{s} \lambda_{k}=1$, then we call,

$$
r_{i j}=\operatorname{IFW} A_{\lambda}\left(\alpha_{1}, \alpha_{2}, \ldots, \alpha_{s}\right)=\sum_{k=1}^{s} \lambda_{k} \alpha_{k}=\left(1-\prod_{k=1}^{s}\left(1-\mu_{\alpha_{k}}\right)^{\lambda_{k}}, \prod_{k=1}^{s} v_{\alpha_{k}}^{\lambda_{k}}\right)
$$

as the intuitionistic fuzzy weighted averaging.

Among them, $r_{i j}=\left(\mu_{i j}, v_{i j}\right)=$ $\left(1-\prod_{k=1}^{s}\left(1-\mu_{\alpha_{k}}\right)^{\lambda_{k}}, \prod_{k=1}^{s} v_{\alpha_{k}}^{\lambda_{k}}\right)$.

\subsection{Group Decision Making Based on the VIKOR Method}

(1) According to group decision information $R=\left[r_{i j}\right]_{m \times n^{\prime}}$, the positive ideal solution $r_{j}^{\bullet}$ and negative ideal solution $r_{j}^{-}$are determined. There are different types of attributes, which are generally divided into efficiency and cost.

$$
\begin{aligned}
& r_{j}^{\bullet}=\left\{\left(\max _{i} r_{i j} \mid j \in J_{1}\right),\left(\min _{i} r_{i j} \mid j \in J_{2}\right)\right\} \\
& r_{j}^{-}=\left\{\left(\min _{i} r_{i j} \mid j \in J_{1}\right),\left(\max _{i} r_{i j} \mid j \in J_{2}\right)\right\}
\end{aligned}
$$

In the formula, $r_{i j}$ is the attribute value of alternative $A_{i}$ about attribute $X_{j}$ and $J_{1}$ and $J_{2}$ are the subsets of benefit and cost objectives respectively.

(2) The group benefits $S_{i}$, individual regrets $R_{i}$ and compromise value $Q_{i}$ of the alternatives.

$$
\begin{gathered}
S_{i}=\sum_{j=1}^{n} \frac{w_{j} d\left(r_{j}^{\bullet}, r_{i j}\right)}{d\left(r_{j^{\bullet}}^{\bullet} r_{j}^{-}\right)}, i=1,2, \ldots, m \\
R_{i}=\max _{j}\left(\frac{w_{j} d\left(r_{j}^{\bullet}, r_{i j}\right)}{d\left(r_{j}^{\bullet}, r_{j}^{-}\right)}\right), i=1,2, \ldots, m \\
Q_{i}=v \frac{S_{i}-S^{\bullet}}{S^{-}-S^{\bullet}}+(1-v) \frac{R_{i}-R^{\bullet}}{R^{-}-R^{\bullet}}, i=1,2, \ldots, m
\end{gathered}
$$

In the formula, $S^{\bullet}=\min _{i} S_{i}, S^{-}=\max _{i} S_{i}, R^{\bullet}=\min _{i} R_{i}, R^{-}=\max _{i} R_{i}$, the smaller the values of $S_{i}, R_{i}$ and $Q_{i}$, the better. $v$ is the decision mechanism coefficient, $v=[0,1]$ is the tendency of decision makers to group opinions and individual regrets. If $v>0.5$, which means that the decision-maker prefers to make decisions according to the way of maximizing the proportion of group benefits, if $v<0.5$, which means that he or she prefers to make decisions by minimizing individual regrets, and $v=0.5$ means that the decision-maker does not have obvious preferences and adopts balanced compromise. In the VIKOR method, $v=0.5$ is generally taken as an equilibrium compromise to maximize group benefits and minimize individual regrets.

(3) Determining the compromise solution

When the following two conditions are satisfied, the alternative can be sorted according to the value of $Q_{i}(i=1,2, \ldots, m)$. The smaller the value, the better the alternative. Let the alternative 
corresponding to the minimum $Q_{i}$ be $A_{i}$. If the minimum $Q_{i}$ satisfies both the following conditions $C_{1}$ and $C_{2}$, then the alternative $A_{i}$ is the best compromise solution.

Condition $C_{1}$ : Acceptability advantage $Q_{2}-Q_{1} \geq 1 /(m-1)$. In the formula, $Q_{1}$ and $Q_{2}$ are the minimum and sub-minimum combined values sorted by $Q_{i}(i=1,2, \ldots, m)$ respectively, and $m$ is the number of alternatives.

Condition $C_{2}$ : In order $Q_{i}$, the $S_{i}$ value or $R_{i}$ value corresponding to the best alternative $A_{i}$ is also the smallest.

If the above two conditions are not valid at the same time, the obtained compromise solution can be divided into two kinds: if condition $C_{1}$ is not satisfied, then $A_{1}, A_{2}, \ldots, A_{r}$ is the compromise solution, in which the maximum value of $r$ is determined by $Q_{r}-Q_{1}<1 /(m-1)$, and these solutions are close to ideal alternative; if condition $C_{2}$ is not satisfied, alternatives $A_{1}$ and $A_{2}$ are the compromise solution.

\subsection{Algorithm Steps}

1. To normalize objective attribute values, and transform the linguistic variables into intuitionistic fuzzy numbers, calculate the objective weight $\lambda_{k}$ of experts by Equations (12) and (13);

2. To aggregate the individual information $D^{k}=\left[x_{i j}^{k}\right]_{m \times n}$ of experts by using the Equation (14) intuitionistic fuzzy number weighted average operator (IFWA) to form a complete group decision matrix $R=\left[r_{i j}\right]_{m \times n}$;

3. According to the group decision matrix, to calculate the attribute weight $w_{j}$ by using the entropy value method (8)-(11);

4. To determine the ideal solution $r_{j}^{\bullet}$ and negative ideal solution $r_{j}^{-}$;

5. To calculate the group benefits value $S_{i}$, individual regrets value $R_{i}$ and compromise value $Q_{i}$ of alternatives by Equations (17)-(19);

6. According to the value of $S_{i}, R_{i}$ and $Q_{i}$, they are sorted in descending order. The smaller the value, the better the alternative.

7. Determine a compromise.

\section{Case Study of the Offshore Wind Power Transmission}

\subsection{Overview of Offshore Wind Power Projects}

In 2015, the TenneT company implemented its first large-scale offshore connection project, by installing BorWin2 offshore platform BorWin beta in the North Sea of Borkum Island through Siemens, which enabled BorWin2 and HelWin1 in Germany, these two offshore wind farms are connected to the grid for the first time. This platform is constructed by the German Warnemunde Shipyard. It uses a voltage level of $(300 \mathrm{kV})$ and has a transmission capacity of $800 \mathrm{MW}$. It is $125 \mathrm{~km}$ away from land. It is the farthest offshore converter platform in the world.

\subsection{Decision Analysis}

The BorWin2 project is $125 \mathrm{~km}$ away from land and $800 \mathrm{MW}$ installed capacity. It belongs to a long-distance and large-capacity offshore wind farm. Three transmission modes have been worked out. Expressed by $A_{i}(i=1,2,3)$, they are the HVAC transmission mode, VSC-HVDC transmission mode and hybrid HVDC transmission mode. Since the transmission distance $(125 \mathrm{~km})$ and transmission capacity $(800 \mathrm{MW})$ have been determined, eight other evaluation indexes in the evaluation system of offshore wind power transmission mode have been selected. Expressed by $X_{j}(j=1,2, \ldots, 8)$, Among them, $X_{2} \sim X_{4}$ and $X_{6} \sim X_{7}$ are cost indexes, the rest are benefit indexes, $X_{1} \sim X_{3}$ are objective indexes, $X_{4} \sim X_{8}$ are subjective indexes, as shown in Table 2 below. 
Table 2. Evaluation indexes of transmission mode.

\begin{tabular}{cccc}
\hline Sign & Evaluation Indexes & Data Type & Index Type \\
\hline$X_{1}$ & Voltage level & Interval numbers & $\mathrm{B}$ \\
$X_{2}$ & Project cost & Real numbers & $\mathrm{C}$ \\
$X_{3}$ & The construction difficulty degree & Real numbers & $\mathrm{C}$ \\
$X_{4}$ & Line loss & Language variables & $\mathrm{C}$ \\
$X_{5}$ & Reliability & Language variables & $\mathrm{B}$ \\
$X_{6}$ & Impact of noise & Intuitionistic fuzzy numbers & $\mathrm{C}$ \\
$X_{7}$ & Impact of radiation & Intuitionistic fuzzy numbers & $\mathrm{C}$ \\
$X_{8}$ & Technology maturity & Intuitionistic fuzzy numbers & $\mathrm{B}$ \\
\hline
\end{tabular}

Three groups of experts with offshore wind power construction experience constitute the offshore wind power transmission modes evaluation team. Each expert uses the anonymous method to evaluate the offshore wind power transmission mode. After investigation and statistics, the original data of objectivity indexes of transmission modes are shown in Table 3 below, and the subjective evaluation data of transmission modes by three expert groups are shown in Tables 4-6 below.

Table 3. Objective index values of transmission modes.

\begin{tabular}{cccc}
\hline & $\boldsymbol{X}_{1} / \mathbf{k V}$ & $\boldsymbol{X}_{2} / \mathbf{\epsilon 1 0 0 \mathbf { m }}$ & $\boldsymbol{X}_{3} /$ month \\
\hline$A_{1}$ & {$[35,220]$} & 29.27 & 25 \\
$A_{2}$ & {$[350,500]$} & 28.13 & 20 \\
$A_{3}$ & {$[100,400]$} & 26.55 & 27 \\
\hline
\end{tabular}

Table 4. Subjective evaluation data of transmission modes by expert group $D_{1}$.

\begin{tabular}{cccccc}
\hline & $\boldsymbol{X}_{4}$ & $\boldsymbol{X}_{5}$ & $\boldsymbol{X}_{6}$ & $\boldsymbol{X}_{7}$ & $\boldsymbol{X}_{8}$ \\
\hline$A_{1}$ & VG & MG & $(0.65,0.25)$ & $(0.50,0.40)$ & $(0.75,0.15)$ \\
$A_{2}$ & VP & VG & $(0.50,0,40)$ & $(0.50,0.40)$ & $(0.65,0.25)$ \\
$A_{3}$ & MP & G & $(0.65,0.25)$ & $(0.50,0.40)$ & $(0.15,0.80)$ \\
\hline
\end{tabular}

Table 5. Subjective evaluation data of transmission modes by expert group $D_{2}$.

\begin{tabular}{cccccc}
\hline & $X_{4}$ & $X_{5}$ & $X_{6}$ & $X_{7}$ & $X_{8}$ \\
\hline$A_{1}$ & G & MG & $(0.65,0.25)$ & $(0.25,0.65)$ & $(0.95,0.05)$ \\
$A_{2}$ & VP & EG & $(0.25,0.65)$ & $(0.25,0.65)$ & $(0.75,0.15)$ \\
$A_{3}$ & G & G & $(0.35,0.55)$ & $(0.5,0.4)$ & $(0.15,0.8)$ \\
\hline
\end{tabular}

Table 6. Subjective evaluation data of transmission modes by expert group $D_{3}$.

\begin{tabular}{cccccc}
\hline & $\boldsymbol{X}_{4}$ & $\boldsymbol{X}_{5}$ & $\boldsymbol{X}_{6}$ & $\boldsymbol{X}_{7}$ & $\boldsymbol{X}_{8}$ \\
\hline$A_{1}$ & VG & MP & $(0.35,0.55)$ & $(0.35,0.55)$ & $(0.75,0.15)$ \\
$A_{2}$ & VP & VG & $(0.25,0.65)$ & $(0.35,0.55)$ & $(0.65,0.25)$ \\
$A_{3}$ & $\mathrm{P}$ & $\mathrm{G}$ & $(0.35,0.55)$ & $(0.5,0.4)$ & $(0.15,0.8)$ \\
\hline
\end{tabular}

(1) The objective attribute values of real and interval numbers of transmission modes are normalized, and the attribute values of linguistic variables are transformed into intuitionistic fuzzy numbers by using the transformation relationship between linguistic variables and intuitionistic fuzzy numbers. Then the objective weight $\lambda_{k}(\mathrm{k}=1,2,3)$ of experts is determined by expert trust function according to the subjective attribute values given by three expert groups $D_{1}-D_{3}$. The calculation results are shown in Tables 7 and 8. 
Table 7. The normalized objective index values of transmission modes.

\begin{tabular}{cccc}
\hline & $\boldsymbol{X}_{1}$ & $\boldsymbol{X}_{2}$ & $\boldsymbol{X}_{3}$ \\
\hline$A_{1}$ & {$[0.0517,0.6016]$} & 0.9071 & 0.8000 \\
$A_{2}$ & {$[0.5169,1.3673]$} & 0.9438 & 1.0 \\
$A_{3}$ & {$[0.1447,1.0938]$} & 1.0 & 0.7407 \\
\hline
\end{tabular}

Table 8. Converting the attribute values of language variables into intuitionistic fuzzy numbers.

\begin{tabular}{ccccccc}
\hline & & $\boldsymbol{X}_{4}$ & $\boldsymbol{X}_{5}$ & $\boldsymbol{X}_{6}$ & $\boldsymbol{X}_{7}$ & $\boldsymbol{X}_{8}$ \\
\hline \multirow{4}{*}{$D_{1}$} & $A_{1}$ & $(0.85,0.10)$ & $(0.65,0.25)$ & $(0.65,0.25)$ & $(0.5,0.4)$ & $(0.75,0.15)$ \\
& $A_{2}$ & $(0.15,0.8)$ & $(0.85,0.1)$ & $(0.5,0.4)$ & $(0.5,0.4)$ & $(0.65,0.25)$ \\
& $A_{3}$ & $(0.35,0.55)$ & $(0.75,0.15)$ & $(0.65,0.25)$ & $(0.5,0.4)$ & $(0.15,0.8)$ \\
\hline \multirow{3}{*}{$D_{2}$} & $A_{1}$ & $(0.75,0.15)$ & $(0.65,0.25)$ & $(0.65,0.25)$ & $(0.25,0.65)$ & $(0.95,0.05)$ \\
& $A_{2}$ & $(0.15,0.8)$ & $(0.95,0.05)$ & $(0.25,0.65)$ & $(0.25,0.65)$ & $(0.75,0.15)$ \\
& $A_{3}$ & $(0.25,0.65)$ & $(0.75,0.15)$ & $(0.35,0.55)$ & $(0.5,0.4)$ & $(0.15,0.8)$ \\
\hline \multirow{2}{*}{$D_{3}$} & $A_{1}$ & $(0.85,0.10)$ & $(0.35,0.55)$ & $(0.35,0.55)$ & $(0.35,0.55)$ & $(0.75,0.15)$ \\
& $A_{2}$ & $(0.15,0.8)$ & $(0.95,0.05)$ & $(0.25,0.65)$ & $(0.35,0.55)$ & $(0.65,0.25)$ \\
& $A_{3}$ & $(0.15,0.8)$ & $(0.75,0.15)$ & $(0.35,0.55)$ & $(0.5,0.4)$ & $(0.15,0.8)$ \\
\hline
\end{tabular}

According to the hesitancy degree in subjective attribute value intuitionistic fuzzy numbers given by three expert groups $D_{1}-D_{3}$, three expert trust functions can be obtained, they are $B_{1}(\pi)=0.2018$, $B_{2}(\pi)=0.1519$ and $B_{3}(\pi)=0.1785$ respectively, and the objective weights of the three expert groups are $\lambda_{1}=0.3792, \lambda_{2}=0.2854$ and $\lambda_{3}=0.3354$.

(2) According to the objective weights of experts, the group decision matrix $R=\left[r_{i j}\right]_{3 \times 8}$ is formed by aggregating the individual information of three expert groups with the intuitionistic fuzzy numbers weighted average operator (IFWA) and merging with the objective attribute value information. The calculation results are shown in Table 9.

Table 9. The aggregated group decision matrix $R=\left[r_{i j}\right]_{3 \times 8}$.

\begin{tabular}{ccccccccc}
\hline & $\boldsymbol{X}_{1}$ & $\boldsymbol{X}_{2}$ & $\boldsymbol{X}_{3}$ & $\boldsymbol{X}_{4}$ & $\boldsymbol{X}_{5}$ & $\boldsymbol{X}_{6}$ & $\boldsymbol{X}_{7}$ & $\boldsymbol{X}_{8}$ \\
\hline$A_{1}$ & {$[0.0517,0.6016]$} & 0.9071 & 0.8000 & $(0.8265,0.1123)$ & $(0.5692,0.3257)$ & $(0.5692,0.3257)$ & $(0.3870,0.5112)$ & $(0.8421,0.1096)$ \\
$A_{2}$ & {$[0.5169,1.3673]$} & 0.9438 & 1.0 & $(0.1500,0.8000)$ & $(0.8904,0.0820)$ & $(0.3579,0.5407)$ & $(0.3870,0.5112)$ & $(0.6821,0.2161)$ \\
$A_{3}$ & {$[0.1447,1.0938]$} & 1.0 & 0.7407 & $(0.2592,0.6541)$ & $(0.7500,0.1500)$ & $(0.4860,0.4079)$ & $(0.5000,0.4000)$ & $(0.1500,0.8000)$ \\
\hline
\end{tabular}

(3) According to the aggregated group decision matrix $R=\left[r_{i j}\right]_{3 \times 8^{\prime}}$ the weight is calculated by the entropy method. Firstly, the entropy value of each attribute is calculated, and then the attribute weight $w_{j}$ is calculated. The calculation results are shown in Table 10.

Table 10. Attribute weights $w_{j}(j=1,2, \ldots, 8)$.

\begin{tabular}{ccccccccc}
\hline & $\boldsymbol{X}_{1}$ & $\boldsymbol{X}_{2}$ & $\boldsymbol{X}_{3}$ & $\boldsymbol{X}_{4}$ & $\boldsymbol{X}_{5}$ & $\boldsymbol{X}_{6}$ & $\boldsymbol{X}_{7}$ & $\boldsymbol{X}_{8}$ \\
\hline$E\left(X_{j}\right)$ & 0.5829 & 0.1302 & 0.3648 & 0.6925 & 0.6900 & 0.9731 & 0.4676 & 0.6678 \\
$w_{j}$ & 0.1216 & 0.2535 & 0.1851 & 0.0896 & 0.0903 & 0.0078 & 0.1552 & 0.0968 \\
\hline
\end{tabular}

(4) According to the aggregated group decision matrix $R=\left[r_{i j}\right]_{3 \times 8^{\prime}}$, the ideal solution $r_{j}^{\bullet}$ and negative ideal solution $r_{j}^{-}$are determined.

$$
\begin{aligned}
& r_{j}^{*}=\{[0.5169,1.3673], 0.9071,0.7047,(0.1500,0.8000),(0.8904,0.0820),(0.3569,0.5407),(0.3870,0.5112),(0.8421,0.1096)\} \\
& r_{j}^{-}=\{[0.0517,0.6016], 1.0000,1.0000,(0.8265,0.1123),(0.5692,0.3257),(0.5692,0.3267),(0.5000,0.4000),(0.1500,0.8000)\}
\end{aligned}
$$


(5) The group benefits value $S_{i}$, individual regrets value $R_{i}$ and compromise value $Q_{i}$ of alternatives are calculated and sorted in descending order. Here, $v=0.5$. The calculation results are shown in Table 11.

Table 11. The group utility value $S_{i}$, individual regret value $R_{i}$ and compromise value $Q_{i}$ of alternatives.

\begin{tabular}{ccccccc}
\hline & \multicolumn{2}{c}{$S_{i}$} & \multicolumn{2}{c}{$R_{i}$} & \multicolumn{2}{c}{$Q_{i}$} \\
\cline { 2 - 7 } & $\begin{array}{c}\text { Calculated } \\
\text { Value }\end{array}$ & Sorting & $\begin{array}{c}\text { Calculated } \\
\text { Value }\end{array}$ & Sorting & $\begin{array}{c}\text { Calculated } \\
\text { Value }\end{array}$ & Sorting \\
\hline$A_{1}$ & 2.6851 & 1 & 2.3335 & 1 & 1.0000 & 1 \\
$A_{2}$ & 1.2718 & 3 & 1.0643 & 3 & 0 & 3 \\
$A_{3}$ & 2.4504 & 2 & 2.0716 & 2 & 0.8138 & 2 \\
\hline
\end{tabular}

From the calculated $Q_{i}$ value, the alternatives and compromise value are ranked as $A_{2}>A_{3}>A_{1}$, among which the corresponding scheme with the smallest $Q_{i}$ value is $A_{2}$, and then check whether the alternative $A_{2}$ satisfies the other two conditions $C_{1}$ and $C_{2}$ For condition $C_{1}, Q\left(A_{3}\right)-Q\left(A_{2}\right)=0.8138 \geq$ $1 / 3-1=0.5$, satisfies condition $C_{1}$; for condition $C_{2}$, the $S_{i}$ value and $R_{i}$ value of scheme $A_{2}$ are also the smallest and satisfy condition $C_{2}$. Therefore, scheme $A_{2}$ is the optimal transmission mode.

The BorWin2 offshore platform project actually uses the VSC-HVDC transmission mode represented by the scheme $A_{2}$ to merge electrical energy into the German grid. Therefore, in this paper, the selection of transmission mode by the VIKOR method was in line with the actual situation of the case, which verified the feasibility and rationality of this method.

\section{Discussions and Prospective}

The selection of the offshore wind power transmission mode is a multiple attribute decision-making problem involving technology, economy, society and so on. In the analysis, a variety of data types and a large amount of fuzzy information were used. This paper adopted the VIKOR method to solve the problem that the evaluation index was not perfect enough and the fuzzy information could not be effectively processed. Taking the qualitative indexes into full consideration, the fuzzy information was converted into precise numbers, and the selection and comparison of offshore wind power transmission modes were carried out based on actual cases, which verifies the feasibility and rationality of this method. Compared with other methods, this method used group decision-making to determine the weight of experts and introduced expert trust function to make the evaluation results more reasonable. At the same time, this method had clear thinking, simple structure, convenient calculation and strong operability. It could be applied to many decision-making problems in economic management and had wide application value.

In order to explain the method more concisely, this paper only listed three common transmission modes and selected eight indexes to build the evaluation system, which had certain limitations. In reality, there are more complex factors should be taken into consideration. At the same time, the evaluation of fuzzy information was highly dependent on individuals or groups, which varied from person to person. Therefore, a higher requirements on expert knowledge and experience is needed.

Future work could consider constructing a complex evaluation system, with more indexes for the selection of transmission modes. At the same time, new transmission modes can also be considered to provide more support for the development of offshore wind power.

Author Contributions: Conceptualization, N.P. and W.G.; methodology, N.P.; software, N.P.; validation, N.P. and W.G.; investigation, N.P. and W.G.; data curation, N.P. and W.G.; writing-original draft preparation, N.P. and W.G.; writing-review and editing, N.P. and W.G.

Acknowledgments: The authors would like to thank the editor and these anonymous reviewers for their thoughtful comments and constructive suggestions, which greatly helped us to improve the manuscript.

Conflicts of Interest: The authors declare no conflict of interest. 


\section{References}

1. Perveen, R.; Kishor, N.; Mohanty, S.R. Off-shore wind farm development: Present status and challenges. Renew. Sustain. Energy Rev. 2014, 29, 780-792. [CrossRef]

2. Korompili, A.; Wu, Q.; Zhao, H. Review of VSC HVDC connection for offshore wind power integration. Renew. Sustain. Energy Rev. 2016, 59, 1405-1414. [CrossRef]

3. Wu, J.; Wang, Z.X.; Xu, L.; Wang, G.Q. Key technologies of VSC-HVDC and its application on offshore wind farm in china. Renew. Sustain. Energy Rev. 2014, 36, 247-255. [CrossRef]

4. Qiu, S.; Fan, C.; Cheng, L.; Qiao, L. Research on VSC-HVDC control strategy based on large offshore wind power system. J. Eng. 2017, 2017, 1923-1927. [CrossRef]

5. Moawwad, A.; El Moursi, M.S.; Xiao, W. A novel transient control strategy for VSC-HVDC connecting offshore wind power plant. IEEE Trans. Sustain. Energy 2014, 5, 1056-1069. [CrossRef]

6. Moawwad, A.; El Moursi, M.S.; Xiao, W. Advanced fault ride-through management scheme for VSC-HVDC connecting offshore wind farms. IEEE Trans. Power Syst. 2016, 31, 4923-4934. [CrossRef]

7. Tang, G.; Xu, Z. A LCC and MMC hybrid HVDC topology with DC line fault clearance capability. Int. J. Electr. Power Energy Syst. 2014, 62, 419-428. [CrossRef]

8. Torres-Olguin, R.E.; Molinas, M.; Undeland, T. Offshore wind farm grid integration by VSC technology with LCC-based HVDC transmission. IEEE Trans. Sustain. Energy 2012, 3, 899-907. [CrossRef]

9. Jung, J.J.; Cui, S.; Lee, J.H.; Sul, S.K. A new topology of multilevel VSC converter for a hybrid HVDC transmission system. IEEE Trans. Power Electron. 2017, 32, 4199-4209. [CrossRef]

10. Zhou, H.; Yang, G.; Wang, J. Modeling, analysis, and control for the rectifier of hybrid HVDC systems for DFIG-based wind farms. IEEE Trans. Energy Convers. 2011, 26, 340-353. [CrossRef]

11. Ruddy, J.; Meere, R.; O'Donnell, T. A comparison of VSC-HVDC with low frequency ac for offshore wind farm design and interconnection. Energy Procedia 2015, 80, 185-192. [CrossRef]

12. Eeckhout, B.V.; Hertem, D.V.; Reza, M.; Srivastava, K.; Belmans, R. Economic comparison of VSC HVDC and HVAC as transmission system for a $300 \mathrm{mw}$ offshore wind farm. Eur. Trans. Electr. Power 2010, 20, 661-671. [CrossRef]

13. Sousa, T.; Dos Santos, M.L.; Jardini, J.A.; Casolari, R.P.; Nicola, G.L.C. An evaluation of the HVDC and HVAC transmission economic. In Proceedings of the 2012 Sixth IEEE/PES Transmission and Distribution: Latin America Conference and Exposition (T\&D-LA), Montevideo, Uruguay, 3-5 September 2012; pp. 1-6.

14. Negra, N.B.; Todorovic, J.; Ackermann, T. Loss evaluation of HVAC and HVDC transmission solutions for large offshore wind farms. Electr. Power Syst. Res. 2006, 76, 916-927. [CrossRef]

15. Wang, L.; Thi, M.S.N. Comparative stability analysis of offshore wind and marine-current farms feeding into a power grid using HVDC links and HVAC line. IEEE Trans. Power Deliv. 2013, 28, 2162-2171. [CrossRef]

16. Chou, C.J.; Wu, Y.K.; Han, G.Y.; Lee, C.Y. Comparative evaluation of the HVDC and HVAC links integrated in a large offshore wind farm-An actual case study in Taiwan. IEEE Trans. Ind. Appl. 2012, 48, 1639-1648. [CrossRef]

17. An, T.; Tang, G.; Wang, W. Research and application on multi-terminal and DC grids based on VSC-HVDC technology in China. High Volt. 2017, 2, 1-10. [CrossRef]

18. Gustavsen, B.; Mo, O. Variable transmission voltage for loss minimization in long offshore wind farm AC export cables. IEEE Trans. Power Deliv. 2017, 32, 1422-1431. [CrossRef]

19. Benasla, M.; Allaoui, T.; Brahami, M.; Denaï, M.; Sood, V.K. HVDC links between north Africa and Europe: Impacts and benefits on the dynamic performance of the European system. Renew. Sustain. Energy Rev. 2018, 82, 3981-3991. [CrossRef]

20. Ingemansson, D.; Wheeler, J.D.; Macleod, N.M.; Gallon, F.; Ruiton, O. The South—West scheme: A new HVAC and HVDC transmission system in Sweden. In Proceedings of the 10th IET International Conference AC and DC Power Transmission (ACDC 2012), Birmingham, UK, 4-5 December 2012; pp. 1-5.

21. Rao, H. Architecture of Nan'ao multi-terminal VSC-HVDC system and its multi-functional control. CSEE J. Power Energy Syst. 2015, 1, 9-18. [CrossRef]

22. Serrano, G.J.; Burgos, P.M.; Riquelme, S.J. Optimum design of transmissions systems for offshore wind farms including decision making under risk. Renew. Energy 2013, 59, 115-127. [CrossRef]

23. Wan, S.P.; Yuan, F.F.; Dong, J.Y. Extended VIKOR method for multiple criteria decision-making with linguistic hesitant fuzzy information. Comput. Ind. Eng. 2017, 112, 305-319. 
24. Prakash, C.; Barua, M.K. A combined MCDM approach for evaluation and selection of third-party reverse logistics partner for Indian electronics industry. Sustain. Prod. Consum. 2016, 7, 66-78. [CrossRef]

25. You, X.Y.; You, J.X.; Liu, H.C.; Zhen, L. Group multi-criteria supplier selection using an extended VIKOR method with interval 2-tuple linguistic information. Expert Syst. Appl. 2015, 42, 1906-1916. [CrossRef]

26. Gupta, H. Evaluating service quality of airline industry using hybrid best worst method and VIKOR. J. Air Transp. Manag. 2018, 68, 35-47. [CrossRef]

27. Shojaei, P.; Seyed Haeri, S.A.; Mohammadi, S. Airports evaluation and ranking model using Taguchi loss function, best-worst method and VIKOR technique. J. Air Transp. Manag. 2018, 68, 4-13. [CrossRef]

28. Seyed Haeri, M.N.; Alireza, S.A. A new multi-criteria decision making approach for sustainable material selection problem: A critical study on rank reversal problem. J. Clean. Prod. 2018, 182, 466-484.

29. Rajesh, R. Measuring the barriers to resilience in manufacturing supply chains using Grey Clustering and VIKOR approaches. Measurement 2018, 126, 259-273. [CrossRef]

30. Ali, Y.; Razi, M.; Felice, F.D.; Sabir, M.; Petrillo, A. A VIKOR based approach for assessing the social, environmental and economic effects of "smog" on human health. Sci. Total Environ. 2019, 650, 2897-2905. [CrossRef]

31. Mateusz, P.; Danuta, M.; Małgorzata, Ł.; Mariusz, B.; Kesra, N. TOPSIS and VIKOR methods in study of sustainable development in the EU countries. Procedia Comput. Sci. 2018, 126, 1683-1692. [CrossRef]

32. Vindeby Offshore Wind Farm Latest News. Available online: https:/www.4coffshore.com/windfarms/ ravnsborg-denmark-dk06.html (accessed on 17 September 2019).

33. Alegría, I.M.; Martín, J.L.; Kortabarria, I.; Andreu, J.; EreñO, P.I. Transmission alternatives for offshore electrical power. Renew. Sustain. Energy Rev. 2009, 13, 1027-1038. [CrossRef]

34. Shenai, K. The Invention and Demonstration of the IGBT [A Look Back]. IEEE Power Electron. Mag. 2015, 2, 12-16. [CrossRef]

35. Gowaid, I.A.; Adam, G.P.; Massoud, A.M.; Ahmed, S.; Holliday, D.; Williams, B.W. Quasi two-level operation of modular multilevel converter for use in a high-power dc transformer with DC fault isolation capability. IEEE Trans. Power Electron. 2015, 30, 108-123. [CrossRef]

36. Borwin2, Grid Connection of the Great Class. Available online: https://www.tennet.eu/our-grid/offshoreprojects-germany/borwin2/ (accessed on 17 September 2019).

37. Kalair, A.; Abas, N.; Khan, N. Comparative study of HVAC and HVDC transmission systems. Renew. Sustain. Energy Rev. 2016, 59, 1653-1675. [CrossRef]

38. Muhammad, H.R. 31 - HVDC Transmission. In Power Electronics Handbook, 3rd ed.; Butterworth-Heinemann: Oxford, UK, 2011; pp. 823-849. ISBN 978-0-12-382036-5.

39. Bahrman, M.; Bjorklund, P.E. The New Black Start: System Restoration with Help from Voltage-Sourced Converters. IEEE Power Energy Mag. 2014, 12, 44-53. [CrossRef]

40. Chen, X.; Sun, H.; Wen, J.; Lee, W.J.; Yuan, X.; Li, N. Integrating wind farm to the grid using hybrid multiterminal HVDC technology. IEEE Trans. Ind. Appl. 2011, 47, 965-972. [CrossRef]

41. Alassi, A.; Bañales, S.; Ellabban, O.; Adam, G.; MacIver, C. HVDC Transmission: Technology Review, Market Trends and Future Outlook. Renew. Sustain. Energy Rev. 2019, 112, 530-554. [CrossRef]

42. Wang, Y.P.; Zhao, W.Q.; Yang, J.M. Hybrid high-voltage direct current transmission technology and its development analysis. Autom. Electr. Power Syst. 2017, 41, 156-167.

43. Flåten, I.; Bergna-Diaz, G.; Sanchez, S.; Tedeschi, E. Control of HVDC systems based on diode rectifier for offshore wind farm applications. Energy Procedia 2017, 137, 406-413. [CrossRef]

44. Pierri, E.; Binder, O.; Hemdan, N.G.A.; Kurrat, M. Challenges and opportunities for a European HVDC grid. Renew. Sustain. Energy Rev. 2017, 70, 427-456. [CrossRef]

45. Guadalupe, A.G.; Pedro, C.R.; Antonio, G.E. Future power transmission: Visions, technologies and challenges. Renew. Sustain. Energy Rev. 2018, 94, 285-301.

46. Opricovic, S.; Tzeng, G.H. Extended VIKOR method in comparison with outranking methods. Eur. J. Oper. Res. 2007, 178, 514-529. [CrossRef]

47. Atanassov, K.T. Intuitionistic fuzzy sets. Fuzzy Sets Syst. 1986, 20, 87-96. [CrossRef]

48. Delgado, M.; Verdegay, J.L. On aggregation operations of linguistic labels. Int. J. Intell. Syst. 1993, 8, 351-370. [CrossRef] 
49. Liu, H.C.; You, J.X.; You, X.Y.; Shan, M.M. A novel approach for failure mode and effects analysis using combination weighting and fuzzy VIKOR method. Appl. Soft Comput. 2015, 28, 579-588. [CrossRef]

50. Xu, Z. Intuitionistic Fuzzy Aggregation Operators. IEEE Trans. Fuzzy Syst. 2007, 15, 1179-1187.

(C) 2019 by the authors. Licensee MDPI, Basel, Switzerland. This article is an open access article distributed under the terms and conditions of the Creative Commons Attribution (CC BY) license (http://creativecommons.org/licenses/by/4.0/). 